\title{
An overview of masonry creep
}

\author{
A. Taliercio \\ Department of Structural Engineering, Politecnico di Milano, Italy
}

\begin{abstract}
This paper intends to give a state of the art overview on the experimental and theoretical studies regarding masonry creep, considering several papers published on this subject in the last two decades. Both new and historic masonry are addressed. Linear viscoelastic behaviour can be assumed in the analysis of masonry under service loads, whereas damage effects must be taken into account when analyzing the effects of heavy sustained loads, as in the case of several historic buildings. Finally, some applications are shown of a model to the prediction of the time evolution of creep-induced damage in historic masonry towers.
\end{abstract}

Keywords: masonry, creep, damage.

\section{Introduction}

According to Webster's Dictionary, 'creep' is the slow change of dimensions of an object due to prolonged exposure to high temperature or stress, or both. It is well known that creep strains are accompanied by significant stress redistribution in heterogeneous structural elements: this is the case of reinforced concrete elements, and brick (or stone) masonry. Accordingly, the short-term stress state in a masonry wall can considerably differ from the long-term state. In the case of post-tensioned brickwork, creep is accompanied by a prestress loss. The importance of these effects explains the number of papers published, mostly in the last two decades, on this subject: a survey on a few selected papers is presented in Sec. 2.

Another problem that may arise in masonry structures as a consequence of creep strains is the decay in material properties associated to cracking. Whereas micro-cracks can damage masonry elements only locally, without implying any severe effect in the short-term, the coalescence and growth of micro-cracks, originating the formation of macro-cracks, can be accompanied by a loss in load 
bearing capacity, which can eventually collapse a structure in the long-term. This is especially true for historic massive masonry buildings, which may locally experience relatively high stresses compared to the material strength properties. Sec. 3 summarizes some experimental results recently obtained on the study of creep-induced damage, and the theoretical modelling of this phenomenon.

Finally, future perspectives of the research in this field are outlined in Sec. 4.

\section{Creep behaviour under service loads}

The study of masonry creep is being systematically addressed since the 80's of last century: amongst the most active researchers in this field, J.J. Brooks, N.G. Shrive and D. Lenczner can be quoted. At the 8th International Brick-Block Masonry Conference $\left(\mathrm{IB}^{2} \mathrm{MaC}\right)$, that took place in Dublin in 1988, a special session (2.3) was devoted to creep in brickwork.

The qualitative strain vs. time plot for masonry at different constant stress levels is shown in Fig. 1. Similarly to concrete and other materials, at constant stress masonry initially exhibits increasing strains at decreasing creep rate (primary creep). Strains can either stabilize after a given time, or keep on increasing at nearly constant rate (secondary creep). If the applied stress is too high compared to the material short-time strength, tertiary creep occurs and the material breaks at constant stress. This phenomenon will be dealt with in Sec. 3, and its consequences in the long-term analysis of ancient masonry structures will be illustrated. In this section, only primary and secondary creep are considered, and the material behaviour can be roughly assumed to be linearly viscoelastic, as permanent strains are usually neglected in these phases.

For linear viscoelastic material, the creep strain at any time $t$ due to the application of a constant stress $\sigma$ at time $t_{0}$ can be expressed as

$$
\varepsilon\left(t, t_{0}\right)=\sigma J\left(t, t_{0}\right)
$$

where $J$ is the creep compliance. For non-aging materials, $J$ simply depends on the time, $t-t_{0}$, elapsed from the application of the stress: setting $t_{0}=0$ for simplicity, $J=J(t)$. Also note that, in fresh masonry, creep and shrinkage develop simultaneously [3].

Some authors directly dealt with the practical problem of estimating the longterm strains in masonry, rather than analyzing the creep evolution law. This information is expressed by the creep coefficient $\left(\phi_{\infty}\right)$, defined as the ratio of the maximum creep strain to the instantaneous (elastic) strain. According to a previous experimental campaign, where different brickwork walls were tested for many years at stress levels within the design stress range (about 1.2 $\mathrm{MPa}$ ), Lenczner [12] found that, for single-leaf masonry walls, the creep coefficient is related to the compressive strength of the brick units $\left(f_{B}\right.$, in $\left.\mathrm{MPa}\right)$ by the equation:

$$
\phi_{\infty}=4.46-0.33 \sqrt{ } f_{B} .
$$

However, testing masonry walls for nearly one year at stress levels outside the design stress range $(0.5,3.5$ and $6 \mathrm{MPa})$, the author found that eqn (2) 
overestimates the creep coefficient (see Fig. 2). This unexpected result, which should be confirmed by a higher number of tests, might be explained by the fact that, as the applied stress increases, primary creep requires a longer time to develop. As will be seen in Sec. 3, the end of the primary creep phase may be not easy to detect, especially at high stresses where strains do not asymptotically stabilize.

Also note that the secondary creep phase cannot last indefinitely. Rocklike materials start cracking as a certain threshold strain is exceeded. It might be inferred that, if masonry enters the secondary creep phase, sooner or later it will experience tertiary creep and fail (see also Sec. 3.1).

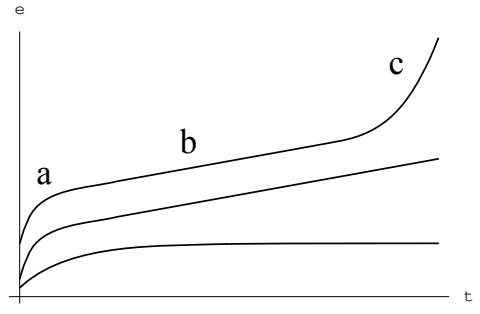

Figure 1: Qualitative strain vs. time plot for masonry subjected to sustained compressive stresses of different intensity: (a) primary, (b) secondary and (c) tertiary creep phases.

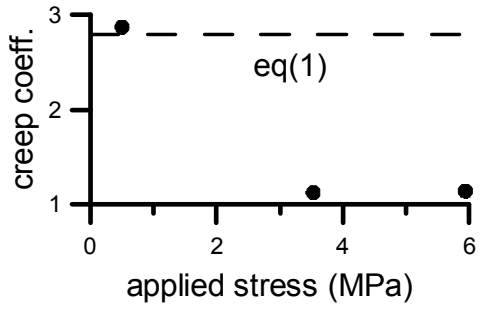

Figure 2: Creep coefficients vs. applied stress for singleleaf masonry walls tested for nearly one year (after [12]).

An attempt to predict the creep coefficient of brickwork according to the properties of the individual constituents was made in [3,5]. Formulae previously established [4] to give the macroscopic 'elastic moduli' of brickwork, according to the mechanical properties and the geometry of bricks and mortar joints, were extended to the creep compliance of masonry, by simply replacing the elastic moduli of the components by some effective moduli.

To mathematically describe the delayed strains in brickwork in the linear viscoelastic field, most laws are borrowed from the study of creep in concrete. Exponential, logarithmic, hyperbolic and power empirical expressions can be employed: a survey of such expressions can be found in [15]. Laws derived from rheological models overcome some drawbacks of the empirical ones, such as the incapability of describing strain recovery upon unloading. Recently, Choi et al. [8] presented a survey on the existing rheological models for masonry creep, the best known of which are the Kelvin model (Fig. 3a) and the Maxwell model (Fig. 3b). The former neglects instantaneous (elastic) strains and is only capable of describing a decrease in creep with time, which occurs at moderately low stresses. The latter predicts a linear creep strain-time relationship, which is experimentally observed at higher stresses after the primary creep phase has elapsed. The Burgers model (Fig. 3c) basically consists of a Kelvin unit and a 
Maxwell unit in series, and accounts for both primary and secondary creep. Referring to Fig. 3c, the creep compliance for a non-ageing Burgers model reads

$$
J=\frac{1}{E_{M}}\left(1+\frac{t}{\tau_{M}}\right)+\frac{1}{E_{K}}\left(1-\exp \left(-t / \tau_{K}\right)\right),
$$

where the 'relaxation times' $\tau_{K}, \tau_{M}$ are related to the viscosities of the dashpots by $\tau_{i}=\eta_{i} / E_{i}(i=K, M)$. Note that $E_{M}$ is the instantaneous elasticity modulus of the material. The authors proposed also a modified Maxwell model, which describes instantaneous strains followed by primary creep [8].

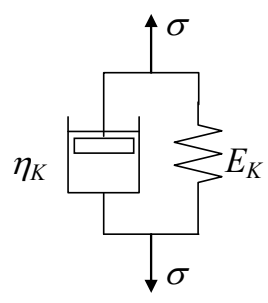

(a) Kelvin

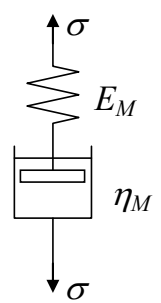

(b) Maxwell

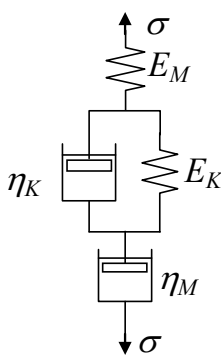

(c) Burgers

Figure 3: Rheological models.

Shrive et al. [21] applied these models to describe the creep behaviour of masonry specimens. They found that the Burgers model can reasonably fit the experimental creep curves provided that the creep compliance, eqn (3), is empirically modified as follows:

$$
J=\frac{1}{E}\left(1+\frac{t^{0.3}}{\tau}\right)+\frac{1}{E}(1-\exp (-t / \tau)),
$$

as the authors arbitrarily assume $E_{K}=E_{M}=E$ and $\tau_{K}=\tau_{M}=\tau$. According to [9], the relaxation time $\tau$ can be related to the elasticity modulus (in $\mathrm{MPa}$ ) by

$$
1 / \tau=0.112-3.35 \times 10^{-6} E .
$$

The authors employed eqns (4) and (5) to satisfactorily model the results obtained during a 8-year-long test programme, where the influence of different parameters (such as moisture content, mortar type and stress level) on the creep behaviour of masonry specimens was investigated. They also found that, extrapolating the results of their tests to 30 years, the creep coefficients proposed by different international standards (with the exception of the Canadian code) underestimate the experimental ones. In most cases, the modified Burgers model captures also the extrapolated results. Reda Taha et al. [19], however, showed that the accuracy in predicting the creep behaviour of masonry prisms using Artificial Neural Networks is definitely superior to that obtainable using the modified Burgers model, due to the large number of parameters involved. 
One might wonder which is the time needed by primary creep to fully develop under service loads, that is, at stress levels which should correspond to a stabilization of strains after a certain time. Hughes and Harvey [10] tried to answer this question, analyzing the data collected on a nine-storey brick masonry tower over a period of about 15 years. Most of the axial strain, either measured in the individual brick units or on the global assembly, occurred during the 1000 days ( 3 years) of observation, corresponding to the end of the construction and the full occupation of the building, and did not significantly increase later. On the contrary, significant lateral strains were still developing in the bricks after 15 years. A reason might be that the competition between compressive strains and shrinkage leads to a nearly zero creep rate in the axial direction, whereas the lateral strains in the bricks, due to Poisson's effect, are enhanced by the brick expansion due to moisture uptake.

The contribution of the mortar joints to the global creep of masonry is discussed by Sayed-Ahmed et al. [20]. According to the results of the experimental program mentioned above, they found that the joints are responsible for 60 to $80 \%$ of the masonry creep, although they constitute only about $20 \%$ of the brickwork.

Referring to dry-stacked masonry, however, Marzahn and König [13] found that the global deformation of masonry is greater than that of the units. Dry joints contribute to masonry creep, as partial crushing of the rough surfaces between the units occurs, mostly at the beginning of the loading phase; accordingly, joint consolidation leads to permanent strains. This phenomenon is likely to be even more pronounced in heavy stone masonry. Tourists visiting the impressive ruins around Cuzco, Peru (Fig. 4), are told that 'it is impossible to insert even a razor blade' between two stones because of the skill of the ancient Inca masters, but creep would account for such tightness in a less poetic, but more realistic way. The authors investigated also the effects of stress level and unit strength on the creep of dry-stacked masonry, finding that, similarly to concrete, the long-term strength the tested brickwork ranges between 80 and $85 \%$ of the instantaneous strength.

\section{Creep behaviour under heavy loads}

When subjected to sustained stresses relatively high if compared to its short-time strength, masonry can fail due to the coalescence and unstable growth of microcracks induced by creep strains. This situation occurs more frequently in massive historic structures rather than in recent brickwork, due to the poorer mechanical properties of ancient masonry. This phenomenon is believed to be the reason for the recent collapse of some medieval towers (Pavia, Italy, 1989; Goch, Germany, 1993; Zichem and Meldert, Belgium, 2006). As it can take years, and even centuries, to take place, creep-induced failure is an extremely insidious event. In the case of fresh concrete, if creep failure does not occur within a few hours it will never occur, as the material strength increases upon application of a sustained load that accelerates hydration [22]. This is not the case of ancient masonry, whose strength is not expected to increase in time, but 
rather to decrease due to material degradation. The critical stress below which creep failure will not occur in fresh concrete is around $0.95 \times$ the material compressive strength [22]. Similar information is not currently available for masonry. Creep tests carried out on prisms of old masonry showed that secondary creep occurred at nearly $40 \%$ of the estimated material strength; failure occurred at about $70 \%$ of the estimated material strength after a few hundreds of days at constant load (see [2], Sec. 2).

An exhaustive survey on the creep-induced failure of historic masonry has been recently reported in a book edited by Binda [2]. In the following sections, a few experimental and theoretical results reported in that book are briefly summarized.

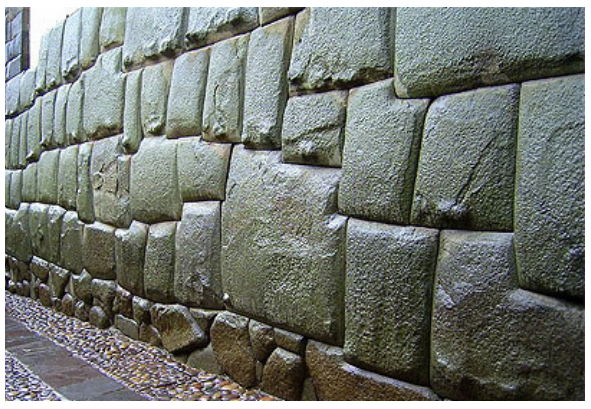

Figure 4: Heavily compacted drystacked stone masonry in Cuzco, Peru.

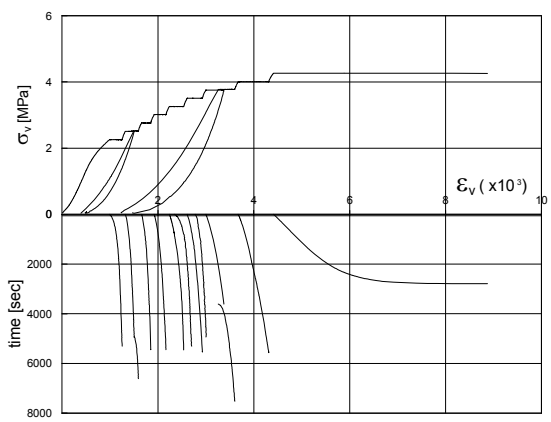

Figure 5: Typical stress-strain and strain-time plots obtained during accelerated creep tests on a masonry specimen subjected (after [17]).

\subsection{Experimental tests}

A considerable number of creep tests were carried out at Politecnico di Milano on masonry specimens taken from historic buildings, by the research group coordinated by Prof. Luigia Binda. Most tests were 'accelerated' (or pseudo-) creep tests, that is, tests consisting of a number of small load steps, which were kept constant for a given time: the last step corresponded to the failure of the specimen. A few 'true' creep tests were also carried out, with the load being kept constant for about 3 years before the failure of the specimen. Only uniaxial compression tests were carried out. A typical strain-time plot obtained in these tests is shown in Fig. 5.

Similarly to concrete, a strict correlation was found to exist between (axial) secondary creep rate during the last load step $\left(\Delta \varepsilon_{v} / \Delta t\right)$ and time to failure (see Fig. 6). Provided that the trend outlined by the tests carried out so far was confirmed by tests of longer duration, times to failure of a few centuries would be matched by secondary creep rates of the order of $10^{-6} \mu \varepsilon / \mathrm{s}$ (i.e. strain 


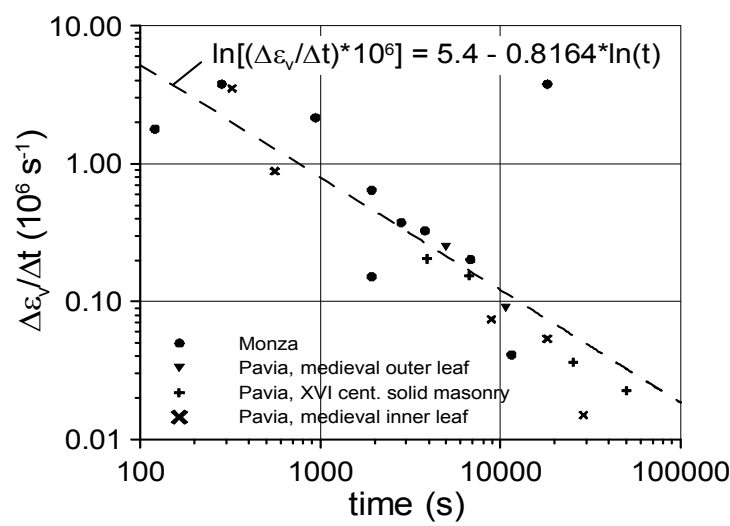

Figure 6: Secondary creep rate vs. time to failure for masonry specimens subjected to pseudo-creep tests (after [2], Sec. 2 courtesy of Prof. Anzani).

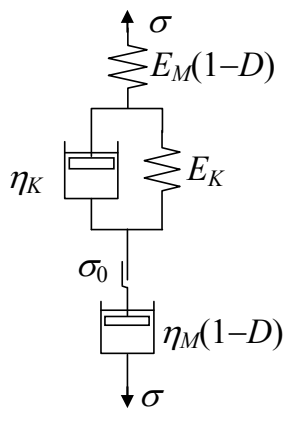

Figure 7: Modified Burgers model.

increments of the order of $10^{-5}$ per year). This is an extremely low rate, which might be difficult to assess. The risk exists of neglecting such rate, erroneously assuming that strains have stabilized under the given loads.

\subsection{Numerical modelling}

To model the experimental tests mentioned in Sec. 3.1, the Burgers rheological model (Fig. 3c) was modified to incorporate damage effects, as shown in Fig. 6. The Kelvin element of the Burgers model was not modified, as primary creep is assumed not to be affected by damage. Damage is confined within the Maxwell element of the model: the instantaneous (elastic) stiffness, $E_{M}(1-D)$, decreases as damage increases, and so does the viscosity $\eta_{M}(1-D)$. This modification makes the model capable of describing creep failure under sustained stress. A slide prevents secondary (and tertiary) creep from activating below a certain stress level $\left(\sigma_{0}\right)$. Accommodating damage variables in rheological models to describe creep-induced failure is an idea exploited also by other authors (see e.g. [6]).

The creep compliance of the modified Burgers model can be obtained from eqn (3) replacing $E_{M}$ by $E_{M}(1-D)$.

As no specific proposal exists for masonry so far, the damage evolution laws are borrowed from other materials. Under increasing stresses, a law is employed similar to that proposed in [11] for concrete:

$$
D=1-\frac{1}{1+A\left\langle y-y_{0}\right\rangle^{B}} .
$$

$y$ is an equivalent strain measure, which is defined as $1 / 2 \varepsilon^{2}$ in the uniaxial case. $y_{0}$ is a strain threshold, below which damage does not evolve. $A$ and $B$ are material 
parameters; similarly to $y_{0}, A$ and $B$ can take different values in tension and compression. \langle\rangle are McAuley brackets.

Under sustained stresses a law proposed for rocksalt is employed, whose creep behaviour was extensively investigated by several researchers (see e.g. [7]):

$$
\dot{D}=x_{1} D y^{x_{2}}(-\log D)^{x_{3}} .
$$

$x_{1}, x_{2}$ and $x_{3}$ are material parameters, which take different values in tension and compression. The equivalent strain $y$ replaces the equivalent stress involved in the original formulation. An alternative empirical expression for the creepinduced damage evolution law was proposed by Shrive and Reda Taha (see [2], Sec. 4).

Figure 8 shows comparison between the results of some (pseudo-) creep tests and their numerical simulations. The model parameters obtained by best fitting the test data and employed in the simulations are summarized in Table 1.
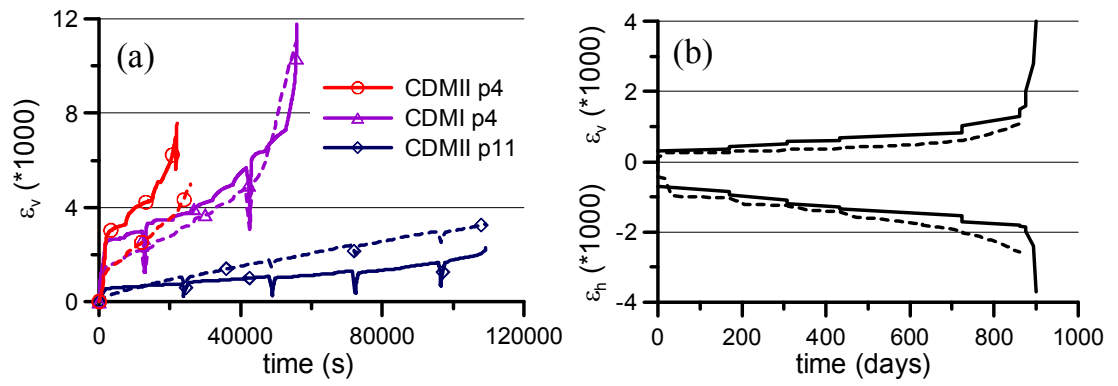

Figure 8: $\quad$ Pseudo-creep tests on historic masonry specimens: comparison between experimental results (solid lines) and numerical simulations (dashed lines). The specimens were taken (a) from the crypt of Monza cathedral (after [18]) and (b) from the ruins of Pavia tower (after [2]).

The constitutive laws (6) and (7) were generalized to the $3 \mathrm{D}$ case, as explained in [16], and implemented in commercial FE codes, which were employed to analyze the time evolution of damage in a couple of masonry towers located in Northern Italy, namely, the Pavia Civic Tower and the Belltower of Monza Cathedral. The former collapsed in 1989: thus, its time to failure could be used as a benchmark for the long-term numerical analyses.

In the analyses, it immediately came out that, using the values for the relaxation time $\tau_{M}$ identified thorough the creep tests, unrealistically short times to failure were obtained. Thus, a parametric study was carried out to find a value that roughly allowed the correct time to failure of Pavia tower to be predicted. In Fig. 9, the vertical displacement at the top of the structural model of Pavia tower is plotted versus time, for different values of $\tau_{M}$. The 'numerical collapse' is assumed to be at the time at which no convergence is obtained in the nonlinear 
Table 1: $\quad$ Model parameter employed in the numerical simulations $(\mathrm{T}=$ tension; $\mathrm{C}=$ compression).

\begin{tabular}{|l|l|l|}
\hline \multirow{2}{*}{$\begin{array}{l}\text { Model } \\
\text { parameter }\end{array}$} & \multicolumn{2}{|c|}{ value } \\
\cline { 2 - 3 } & Pavia & Monza \\
\hline$E_{M}(\mathrm{MPa})$ & 3500 & 2800 \\
\hline$\tau_{M}(\mathrm{sec})$ & 690000 & 110000 \\
\hline$E_{K}(\mathrm{MPa})$ & 30000 & 20000 \\
\hline$\tau_{K}(\mathrm{sec})$ & 7500 & 7500 \\
\hline$v$ & 0.2 & 0.15 \\
\hline$A_{C}$ & $1.43 \times 10^{7}$ & $5.63 \times 10^{7}$ \\
\hline$B_{C}$ & 1.2 & 1.5 \\
\hline$A_{T}$ & $4.74 \times 10^{7}$ & $3.75 \times 10^{7}$ \\
\hline$B_{T}$ & 1.05 & 1.05 \\
\hline$y_{\mathrm{OC}}$ & $5.7 \times 10^{-7}$ & $3.6 \times 10^{-7}$ \\
\hline$y_{\mathrm{O} T}$ & $5.7 \times 10^{-9}$ & $3.6 \times 10^{-9}$ \\
\hline$x_{1 C}\left(\mathrm{sec}^{-1}\right)$ & 86.5 & 629.5 \\
\hline$x_{2 C}$ & 0.45 & 0.55 \\
\hline$x_{3 C}$ & 1.45 & 1.13 \\
\hline$x_{1 T}\left(\mathrm{sec}^{-1}\right)$ & 133.9 & 56 \\
\hline$x_{2 T}$ & 0.35 & 0.25 \\
\hline$x_{3 T}$ & 1.13 & 1.13 \\
\hline
\end{tabular}

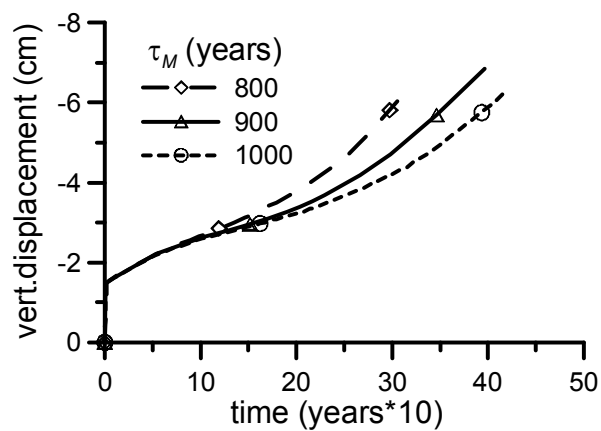

Figure 9: Vertical displacement at the top of Pavia tower FE model vs. time for different values of $\tau_{M}$.

FE analysis. Setting $\tau_{M}=1000$ years allows the correct time to failure of the tower to be correctly captured (approximately 400 years after the construction of a heavy belfry at the top of the tower).

Using the values of the model parameters listed in Table 1 for the specimens extracted from the crypt of Monza cathedral, and using for $\tau_{M}$ the value identified through the FE analysis of Pavia tower, the analysis was carried out of the Belltower of Monza cathedral, which exhibited a severe crack pattern. Figs. $10 \mathrm{a}$ to $\mathrm{d}$ show the contour plots of a measure of the damage variable at different 


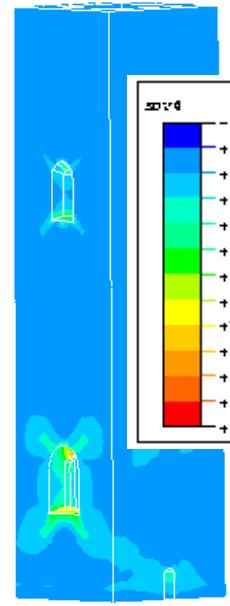

(a)

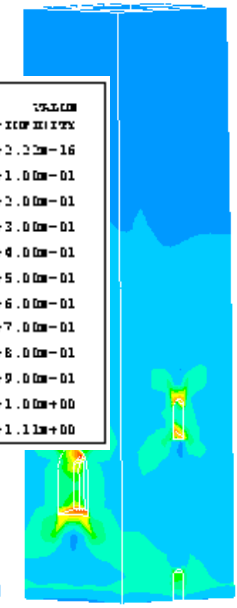

(b)

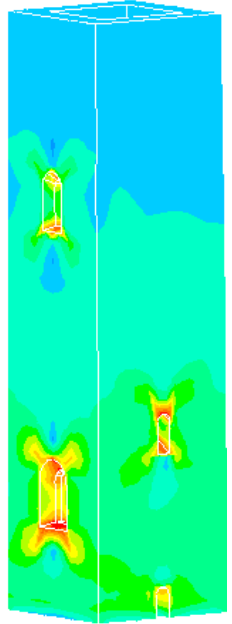

(c)

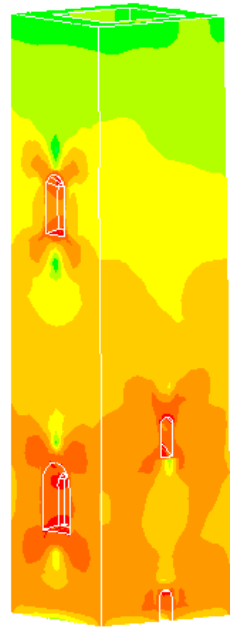

(d)

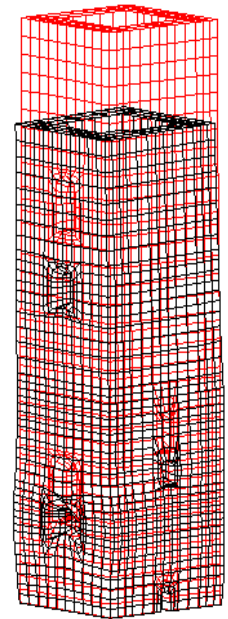

(e)

Figure 10: Damage evolution in the Belltower of Monza cathedral after (a) 150 , (b) 300, (c) 500 and (d) 650 years from the end of the construction; (e) failure mode (after [17]).

times [17]. The 'numerical collapse' occurs at 650 years after the completion of the tower, corresponding to about 2240 AD. The failure mode, shown in Fig. $10 \mathrm{e}$, is a sort of barrelling of the lower part of the tower. This type of deformation is likely to be now prevented by the restoration works recently carried out, that include structural repointing interventions [14].

\section{Conclusions and perspectives}

According to the survey made in this paper, the creep behaviour of brickwork loaded within the service limits has been thoroughly investigated, both experimentally and theoretically. The existing creep laws, both empirical and based on rheological models, have been proven to be sufficiently reliable.

Extensive investigations have still to be carried out on the study of the creepinduced failure of brickwork, which is an important topic especially for historic masonry. The available experimental results constitute an important, but not exhaustive, basis by which future researches have to be driven. Owing to the scatter in the experimental results, and the variety of masonry typologies, much experimental work is still required to achieve a reliable understanding of the stress levels at which masonry can fail as a consequence of creep-induced damage. Also, no experimental information is available at present on the creep behaviour of historic masonry under multiaxial sustained stresses.

A particularly tricky point is the correct detection of the secondary creep phase, which may require long duration tests under relatively high stresses, with an accurate measurement of the secondary creep rate. Indeed, this parameter was 
found to be strictly correlated with the creep time to failure, thus representing an important safety indicator. The correct estimate of the secondary creep rate allows the relaxation time $\tau_{M}$ of the rheological Burgers model to be defined; this parameter was shown to be a fundamental ingredient for the description of the time evolution of damage in masonry structures and for the prediction of their residual life under sustained loads. As it is not always easy to detect whether the material is still experiencing primary creep or has entered the secondary creep phase, it is recommended to monitor the strain changes in historic buildings for a very long time: tests during three years were found not sufficient to allow this parameter to be correctly estimated.

Finally, the problem of mathematically describing creep-induced damage is still an open problem. The model proposed in Sec. 3.2 can be a starting point, but, of course, different and more robust theories can be proposed. In any case, the formulation and calibration of any damage-evolution law must keep pace with the development of extensive testing programmes.

\section{References}

[1] Anzani, A., Binda, L., Taliercio, A., Experimental and numerical study of the long term behaviour of ancient masonry, in 'Structural Studies, Repairs and Maintenance of Heritage Architecture IX', eds. C.A. Brebbia \& A. Torpiano, WIT Press, Southampton (GB), 2005, pp. 577-586.

[2] Binda, L., (ed). Learning from Failure: Long-term Behaviour of Heavy Masonry Structures, WIT Press, Southampton (UK), 2007.

[3] Brooks, J.J., Composite modelling of masonry deformation, Materials and Structures RILEM, 23, pp. 241-251, 1990.

[4] Brooks, J.J., Abdullah, C.S., Composite models for predicting elastic and long-term movements in brickwork walls, Proc British Masonry Society, 1, pp 26-44, 1986.

[5] Brooks, J.J., Abdullah, C.S., Composite model prediction of the geometry effect on creep and shrinkage of clay brickwork, Proc. 8th Int. Brick-Block Masonry Conf., Dublin, Elsevier Appl. Sci., 1, pp. 316-323, 1988.

[6] Cervera, M., Oliver, J., Prato, Th., Thermo-chemo-mechanical model for concrete II: Damage and creep, J. Eng. Mech., ASCE, 125(9), 1028-1039, 1999.

[7] Chan, K.S., Brodski, N.S., Fossum, A.F., Bodner, S.R., Munson, D.E., Damage-induced nonassociated inelastic flow in rock salt, Int. J. Plasticity, 10, 623-642, 1994.

[8] Choi, K.K., Lissel, S.L., Reda Taha, M.M., Rheological modelling of masonry creep, Canadian J. of Civil Engng, 34(11), pp. 1506-1517, 2007.

[9] Hughes, T.G., Harvey, R., On the representation of creep by rheological analogy, Proc. 12th ASCE Structures Conf., pp. 385-396, 1995.

[10] Hughes, T.G., Harvey, R.J., Creep measured in a brick masonry tower block, Masonry International, 9(2), pp. 50-56, 1995.

[11] La Borderie, C., Berthaud, Y., Pijaudier-Cabot, G., Crack closure effect in continuum damage mechanics: numerical implementation, Proc. 2nd Int. 
Conf. on Computer Aided Analysis and Design of Concrete Structures, Zell am See (A), pp. 975-986, 1990.

[12] Lenczner, D., Creep in brickwork walls at high and low stress/strength ratios, Proc. 8th Int. Brick-Block Masonry Conf., Dublin, Elsevier Appl. Sci., 1, pp. 324-333, 1988.

[13] Marzahn, G., König, G., Experimental investigation of long-term behaviour of dry-stacked masonry, J. of the Masonry Society, 20(1), pp. 9-21, 2002.

[14] Modena, C., Valluzzi, M.R., Tongini Folli, R., Binda, L., Design choices and intervention techniques for repairing and strengthening of the Monza cathedral bell-tower, Constr. Build. Mat., 16(7), 385-395, 2002.

[15] Neville, A.M., Dilger, W.H., Brooks, J.J., Creep of Plain and Structural Concrete, Construction Press, London, 1983.

[16] Papa, E., Taliercio, A., A damage model for brittle materials under nonproportional monotonic and sustained stresses, Int. J. Numer. Analyt. Methods Geomech., 29(3), 287-310, 2005.

[17] Papa, E., Taliercio, A., Binda, L., Safety assessment of ancient masonry towers, Proc. $2^{\text {nd }}$ Int. Congr. 'Studies in Ancient Structures' (SAS2001), eds. G. Arun \& N. Seçkin, Istanbul, pp. 345-354, 2001.

[18] Papa, E., Taliercio, A., Binda, L., Creep failure of ancient masonry: experimental investigation and numerical modelling, in 'Structural Studies, Repairs and Maintenance of Historical Buildings VII’, C.A. Brebbia (Ed.), WIT Press, Southampton (GB), 2001, pp. 285-294.

[19] Reda Taha, M.M., Noureldin, A., El-Sheimy, N., Shrive, N.G., Neural network modelling of creep in masonry, Structures \& Buildings, 15(4), pp. 279-292, 2004.

[20] Sayed-Ahmed, E.Y., Shrive, N.G., Tilleman, D., Creep deformation of clay masonry structures: a parametric study, Canadian J. of Civil Engng., 25(1), pp. 67-80, 1998.

[21] Shrive, N.G., Sayed-Ahmed, E.Y., Tilleman, D., Creep analysis of clay masonry assemblages, Canadian J. of Civil Engng., 24(3), pp. 367-379, 1997.

[22] Sousa Coutinho, A., A contribution to the mechanism of concrete creep, Materials and Structures RILEM, 10(1), pp. 3-16, 1977. 